\title{
The Branching Pattern of the Nervus Ischiadicus after Passing through the Foramen Ischiadicum Majus in Hasak Sheep Breed
}

H. Balkaya

10.18805/IJAR.B-1364

\begin{abstract}
Background: Hasak is a sheep breed, developed as a result of crossbreeding studies at Bahri Dağdaş International Agricultural Research Institute. The aim of this study was to examine the macroanatomical structure of the nervus ischiadicus outside the cavum pelvis in Hasak sheep breed.

Methods: 5 Hasak sheep were used for this study. After opening the body cavities of the cadavers, they were fixed in formaldehyde solution. The branches of the nervus ischiadicus were dissected separately and photographed.

Result: It was observed that nervus ischiadicus was emitting nervus gluteus caudalis immediately after leaving the foramen ischiadicum majus. After this branching nervus ischiadicus coursed ventrally and it was divided into two nerves: nervus tibialis and the common root of nervus peroneus communis and nervus cutaneus surae caudalis.
\end{abstract}

Key words: Hasak sheep, Hind limb, Nervus ischiadicus.

\section{INTRODUCTION}

Sheep is the most important species for rural economy in terms of their multifaceted utility (wool, meat, skin, milk and manure) (Verma and Sharma, 2009). It's crucial to arrange the environmental factors in sheep farming (Karabacak et al. 2015). In some sheep species, birth weights can be improved through selection (Nirban et al. 2015).

In Anatolian husbandry, sheep have been a significant element for almost 10000 years from the Neolithic time and currently, it is still important in Turkey's national economy. (Arbuckle et al. 2009) In addition, ancient Central Anatolia played a significant role in the sheep taming process (Zeder, 2008).

Hasak is a sheep breed, developed as a result of crossbreeding studies at Bahri Dağdaş International Agricultural Research Institute between the years of 1989 and 2000 , in order to create the new meat type sheep in Turkey. Hasak sheep type contains $31.25 \%$ Hampshire Down, 31.25\% German Black Head and 37.50\% Akkaraman genotypes (Tekin et al. 2000; Canatan et al. 2014). Hasak sheep name was created from the first syllables of the pure genotype names (based on Turkish pronunciation) (Tekin et al. 2005). This thin-tailed, strong sheep is often used for early lamb production and it is usually pied, black or brown colored; it has a quick growth rate and a good carcass performance (Yilmaz et al. 2013). The root of the tail is rich in fat and the rest part is long (Kaymakci, 2008; Sonmez 2009).

According to the statement written in the $2973^{\text {rd }}$ issue of Turkish Official Newspaper (Statement number: 2014/50), Hasak sheep type is approved as official indigenous animal breed of Turkey (Resmi Gazete, 2014).

The nerves originating from plexus sacralis of mammals are nervus gluteus cranialis, nervus gluteus caudalis, nervus cutaneus femoris caudalis, nervus ischiadicus, nervus
Department of Anatomy, Faculty of Veterinary Medicine, Ataturk University, Erzurum, Turkey.

Corresponding Author: H. Balkaya, Department of Anatomy, Faculty of Veterinary Medicine, Ataturk University, Erzurum, Turkey. Email: hulya.balkaya@atauni.edu.tr

How to cite this article: Balkaya, H. (2021). The Branching Pattern of the Nervus Ischiadicus after Passing through the Foramen Ischiadicum Majus in Hasak Sheep Breed. Indian Journal of Animal Research. DOI: 10.18805/IJAR.B-1364.

Submitted: 27-03-2021 Accepted: 29-09-2021 Online: 07-11-2021

pudendus and nervi rectales caudales (Pasquini et al. 1995; Dursun, 2000). The nervus ischiadicus was branched from plexus sacralis and it passes through foramen ischiadicum majus, from which the cranial and caudal gluteal nerves arise in mixed breed sheep (Vasconcelos et al. 2014).

Studies based on Hasak sheep breed are generally used for zootechnical purposes. No studies about the anatomy of the nervous system of this sheep breed was observed in literature reviews. The majority of the carcass used as meat is constituted by the muscles of the hind limb and gluteal region in Hasak sheep, as in most other butchery animal species. These regions are mostly innervated by nervus ischiadicus. Additionally, nervus ischiadicus and its terminal branches are considerable landmarks for the regional anesthesia of hind limb. The aim of this study was to investigate the branching pattern of the nervus ischiadicus outside the cavum pelvis and to reveal the course of these branches and their innervation zones in Hasak sheep breed.

\section{MATERIALS AND METHODS}

In the present study, a total of 5 female Hasak sheep breeds were used. The study was conducted during the years of 2019-2020 at the Veterinary Anatomy Laboratories of Ataturk 
University Veterinary Faculty. For anaesthesia, $0.05 \mathrm{mg} / \mathrm{kg}$ of xylazine, followed by $2 \mathrm{mg} / \mathrm{kg}$ of ketamine were injected intravenously. Sulcus jugularis of the animals was dissected and the arteria carotis communis was revealed and drained of blood. Then, an incision was made from the pubis to the processus xiphoideus along the linea alba. The muscles and surrounding tissues were dissected and symphysis pelvis was cut with a costatom and the pelvic cavity was opened. The internal organs of the abdominal cavity and pelvic cavity were removed and the cadavers were fixed in $10 \%$ formalin solution. The 5 sets of pelvic limbs were dissected carefully. At the end of the dissection, nervus ischiadicus and its branches after leaving the cavum pelvis were revealed separately and photographed. The terminology used in this article was chosen according to the Nomina Anatomica Veterinaria (2017).

\section{RESULTS AND DISCUSSION}

In Hasak sheep breed, it was observed that nervus ischiadicus was emitting nervus gluteus caudalis immediately after leaving the foramen ischiadicum majus ( Fig 1: 1). After this branch, at the level of the trochanter majus of femur, nervus ischiadicus branched the rami musculares from its caudal aspect. Rami musculares and nervus gluteus caudalis coursed caudally and united after a short distance and this nerve trunk dispersed into musculus gluteus superficialis, musculus biceps femoris, musculus semitendinosus and musculus semimembranosus (Fig 1: 2,3).

After giving the nervus gluteus caudalis, the nervus ischiadicus coursed ventrolaterally parallel to the caudal margin of musculus quadriceps femoris, this course took place between musculus semimembranosus and musculus gluteobiceps. After branching the rami musculares, nervus ischiadicus coursed ventrally; and approximately in the middle of the thigh, it was divided into two nerves: nervus tibialis and the common root of nervus peroneus communis and nervus cutaneus surae caudalis ( Fig 1: 4,5).

At the middle of the thigh, the nervus tibialis originated from the cranial edge of the nervus ischiadicus. After coursing a short distance ventrally, it ramified into six branches between the proximal parts of the caput laterale and caput mediale of the musculus gastrocnemius (Fig 2: $1, a, b, c, d, e, f)$. These branches were innervating musculus popliteus, musculus soleus, musculus gastrocnemius, musculus tibialis caudalis and musculus flexor digitorum superficialis in the caudoproximal region of the crus. After this ramification, nervus tibialis was coursing caudally and travelled parallel to the medial edge of tendo calcaneus communis. At the end of this course, nervus tibialis bifurcated into nervus plantaris lateralis and nervus plantaris medialis at the craniomedial side of the calcaneus. After a short course, nervus plantaris lateralis proceeded between talus and calcaneus by bending laterally and innervated articulatio tarsi, tendon of musculus flexor digitorum profundus and lateral component of the pedis. While the nervus plantaris lateralis proceeded laterally, nervus plantaris medialis coursed at the plantar edge of the pedis.

Nervus cutaneus surae caudalis was the caudal branch of the common root of nervus peroneus communis and nervus cutaneus surae caudalis (Fig 1: 7). It was extending caudally and dispersing in the cranial part of musculus biceps femoris, musculus tensor fascia latae, lateral side of tarsus and the skin and fascia of the caudal part of the crus.

The common root of nervus peroneus communis and nervus cutaneus surae caudalis coursed caudally and divided into nervus cutaneus surae caudalis and nervus peroneus communis at the caudal side of articulatio genu. By coursing to the craniolateral of the crus, as a wide, flat band, the nervus peroneus communis bifurcated into nervus peroneus superficialis and nervus peroneus profundus near the origin of the musculus extensor digitorum lateralis and musculus peroneus tertius (Fig 1: 6; Fig 3: 1,2,3). At this level, nervus peroneus profundus ramified into four branches and spread into musculus peroneus longus, musculus peroneus tertius and caudal part of the musculus tibialis cranialis (Fig 3: 3). After this ramification, nervus peroneus profundus coursed distally and passed through retinaculum extensorium proximale at the cranial side of the articulatio tarsi and travelled towards the dorsum pedis.

It was detected that near the origin of the musculus extensor digitorum lateralis and musculus peroneus tertius,

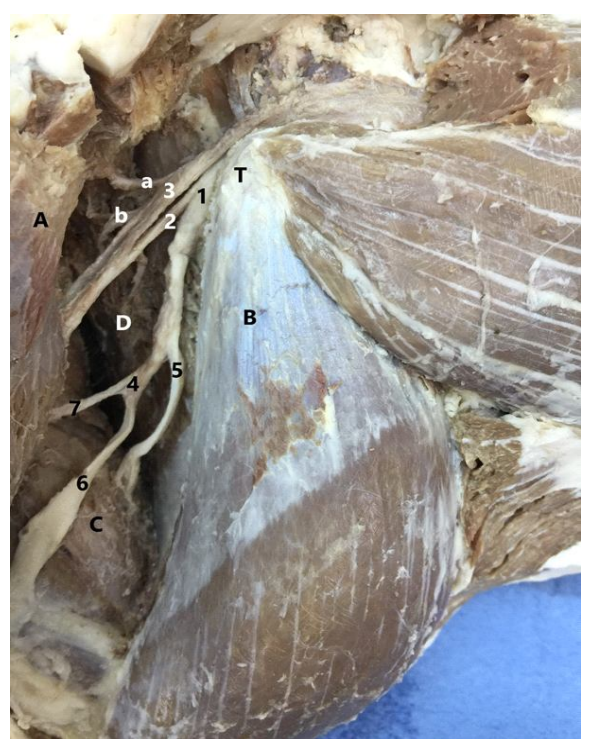

Fig 1: Branches of nervus ischiadicus after foramen ischiadicum majus.

Nervus ischiadicus (1), Rami musculares (2), Nervus gluteus caudalis (3), Common root of nervus peroneus communis and nervus cutaneus surae caudalis (4), Nervus tibialis (5), Nervus peroneus communis (6), Nervus cutaneus surae caudalis (7), Muscular branches of nervus gluteus caudalis (a,b), Musculus gluteobiceps (A), Vastus lateralis of musculus quadriceps femoris (B), Musculus gastrocnemius (C), Musculus semimembranosus (D), Trochanter major of femur (T). 
in the proximolateral part of the crus, one of the two branches of nervus peroneus communis was the nervus peroneus superficialis (Fig 3: 1). This nerve bifurcated just after its origin. The caudal branch of nervus peroneus superficialis, which was the shorter, innervated musculus extensor digitorum lateralis. The cranial branch of nervus peroneus superficialis, which was the longer and stronger, directed distally and proceeded as nervus digitalis dorsalis communis III on the dorsolateral component of the pedis (Fig 4: 1,2). While the nervus digitalis dorsalis communis III passed distally on the lateral side of the retinaculum extensorium proximale, the long branch of nervus peroneus profundus passed through the retinaculum extensorium proximale at the cranial side of the articulatio tarsi.

These findings that were found in this study about branching pattern of nervus ischiadicus has been displayed in all 5 specimens, no significant difference has been observed between the specimens.

It was reported that the nervus ischiadicus proceeded from its source and went through the foramen ischiaticum majus, gave the nervus gluteus cranialis and nervus gluteus caudalis in mixed breed sheep (Vasconcelos et al. 2014). In Hasak sheep breeds examined in this study, nervus gluteus caudalis was derived from nervus ischiadicus immediately after leaving the foramen ischiadicum majus in consistent with the results of Vasconcelos et al. (2014). However, nervus gluteus caudalis originated from the last lumbar spinal nerve and the first and second sacral spinal nerves in Angora goats and Akkaraman sheep (Erden, 1992).

Rami musculares were different in size and released by the nervus ischiadicus to supply the musculus gluteus medius, musculus gluteobiceps, musculus gluteus profundus, musculus gemelli, musculus obturatorius externus, musculus quadratus femoris, musculus semitendinosus, musculus semimembranosus and musculus adductor in sheep (Ghoshal; Getty, 1971). In the current study, contrary to Ghoshal and Getty's (1971) findings, it was found that rami musculares and nervus gluteus caudalis coursed caudally and united after a short distance and this nerve trunk dispersed into musculus gluteus superficialis, musculus biceps femoris, musculus semitendinosus and musculus semimembranosus.

It was reported that the nervus tibialis and nervus peroneus communis were the terminal branches of the nervus ischiadicus, originating distally near the trochanter majus of femur (Godinho et al. 1987; De Lima et al. 2008; Vasconcelos et al. 2014). In the current study, however, in this study it was observed that the terminal branches of the nervus ischiadicus were nervus cutaneus surae caudalis and nervus peroneus communis at the caudal side of articulatio genu.

In sheep, Ghoshal and Getty (1971) indicated that the nervus ischiadicus apparently divided into nervus peroneus communis and nervus tibialis usually $1 \mathrm{~cm}$ distal to the origin of the nervus cutaneus surae caudalis, near the middle of the thigh. Nervus cutaneus surae caudalis dispersed in the fascia and skin on the lateral aspect of the tarsus; and in the majority of the cases, this nerve arose directly from the nervus ischiadicus. In our study, in contrast with Ghoshal and Getty's (1971) findings, nervus cutaneus surae caudalis arose from the common root of nervus peroneus communis and nervus

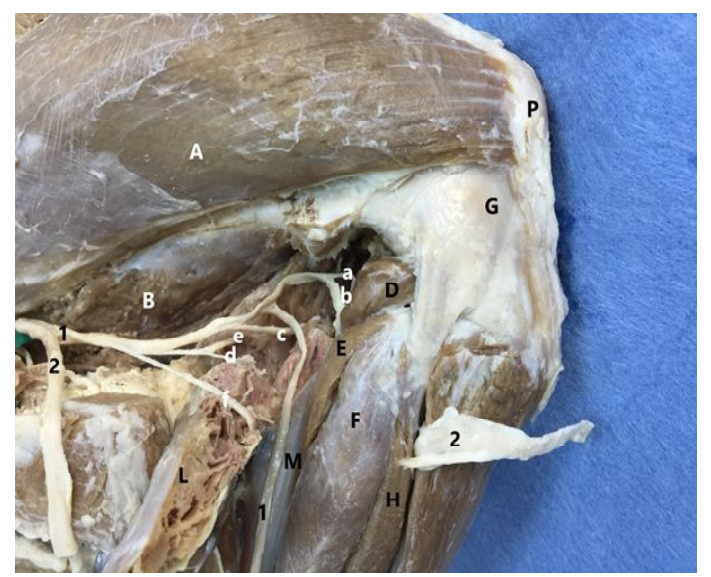

Fig 2: Nervus tibialis.

Nervus tibialis (1), Nervus peroneus communis (2), Muscular branches of nervus tibialis $(a, b, c, d, e, f)$, Vastus lateralis of musculus quadriceps femoris (A), Musculus semimembranosus (B), Musculus popliteus (D), Musculus tibialis caudalis (E), Musculus flexor digiti I longus (F), Regio genu (G), Musculus extensor digitorum lateralis $(H)$, Musculus gastrocnemius caput laterale $(L)$, Musculus gastrocnemius caput mediale $(\mathrm{M})$, Patellar region $(P)$.

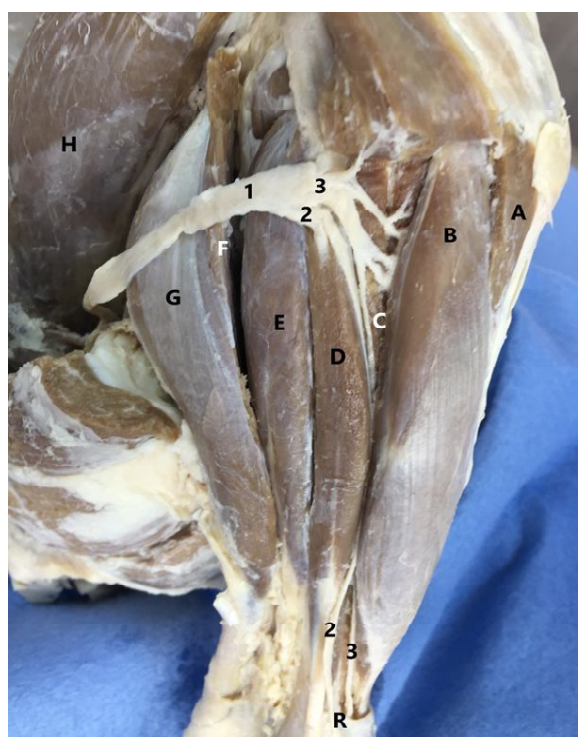

Fig 3: Nervus peroneus communis.

Nervus peroneus communis (1), Nervus peroneus superficialis (2), Nervus peroneus profundus (3), Musculus tibialis cranialis (A), Musculus peroneus tertius (B), Musculus peroneus longus (C), Musculus extensor digitorum lateralis (D), Musculus flexor digiti I longus (E), Musculus tibialis caudalis $(F)$, Musculus gastrocnemius $(G)$, Vastus lateralis of musculus quadriceps femoris $(H)$, Retinaculum extensorium proximale $(R)$. 


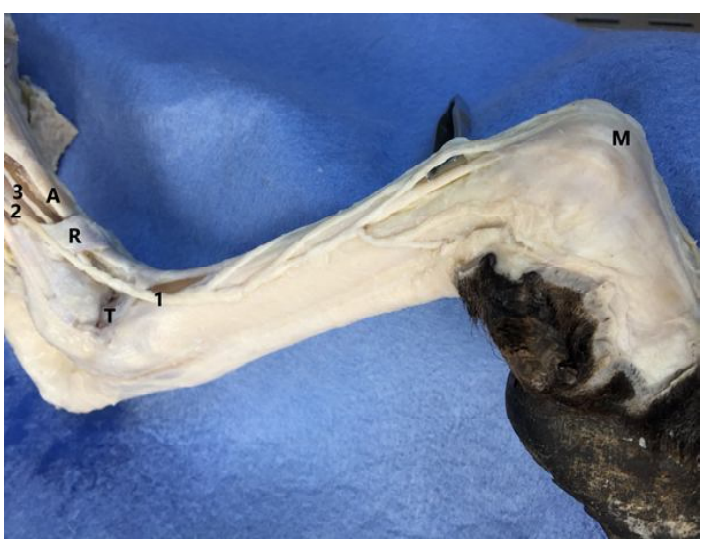

Fig 4: Nervus digitalis dorsalis communis III.

Nervus digitalis dorsalis communis III (1), Nervus peroneus superficialis (2), Nervus peroneus profundus (3), Tendon of musculus peroneus tertius and musculus tibialis cranialis $(A)$, Retinaculum extensorium proximale $(\mathrm{R})$, Regio articulatio tarsi

(T), Regio articulatio metatarsophalangea (M).

cutaneus surae caudalis in Hasak sheep breed, although some researchers indicated that this nerve may also be derived from the nervus peroneus or nervus tibialis (Ghoshal, 1966; Ghoshal and Getty, 1967; Ghoshal and Getty, 1968).

Dursun (2000) reported that nervus tibialis was the thickest nerve among the terminal branches of the nervus ischiadicus. However, Hasak sheep breeds examined in this study, the common root of nervus peroneus communis and nervus cutaneus surae caudalis was the thickest nerve among the terminal branches of the nervus ischiadicus. Some researches described that the nervus tibialis run between the musculus gastrocnemius caput laterale and musculus gastrocnemius caput mediale to reach and supply the caudal muscles of the crus (Pasquini et al. 1995; Dursun, 2000; Dyce et al. 2017). They also reported that it bifurcated into nervus plantaris lateralis and nervus plantaris medialis at the level of the point of the hock. Similar to the findings of the previous studies (Pasquini et al. 1995; Dursun, 2000; Dyce et al. 2017), in Hasak sheep, nervus tibialis ramified into six branches between proximal part of the musculus gastrocnemius caput laterale and musculus gastrocnemius caput mediale. These branches were innervating the caudoproximal region of the crus. After this ramification, it coursed caudally and bifurcated into nervus plantaris lateralis and nervus plantaris medialis at the craniomedial side of the calcaneus.

Erden (1992) displayed that nervus peroneus communis divided into nervus peroneus superficialis and nervus peroneus profundus at the level of the sulcus extensorius of tibia in Akkaraman sheep and Angora goat. This researcher also reported that the nervus peroneus communis continued as nervus digitalis dorsalis communis III in both animal species. Similarly, in the present study, it was observed that the nervus peroneus communis bifurcated into nervus peroneus superficialis and nervus peroneus profundus near the origin of the musculus extensor digitorum lateralis and musculus peroneus tertius at the level of the proximal part of the tibia. The nervus peroneus superficialis, which was the longer and stronger, directed distally and proceeded as nervus digitalis dorsalis communis III.

\section{CONCLUSION}

In summary, in the current study, the macroanatomical structure and branching of the nervus ischiadicus, after it exits the cavum pelvis, in Hasak sheep breed were determined. I believe that the present study will help to understanding the phylogenetic and morphological variety among different species. Additionally, these findings will contribute to the future understanding of the branching patterns of the nervus ischiadicus in other species. The present study is believed to explain the dispersion of nervus ischiadicus through the hind limb of Hasak sheep and ensure specific macroanatomical data in this particular area. These results are also expected to contribute to the knowledge about regional anesthesia applications of the hind limb.

\section{REFERENCES}

Arbuckle, B.S., Oztan, A., Gulcur, S. (2009). The evolution of sheep and goat husbandry in central Anatolia. Anthropozoologica. 44: 129-157.

Canatan, T., Kan, M., Kirbas, M., Akay, N., Yilmaz, O. (2014). Adult Live Weight Estimates of Hasmer and Hasak Sheep with Their Some Body Measurements. Conference: Balkan Agriculture Congress, 08-10 September 2014, Edirne.

De Lima, E.M.M., Silva, F.O.C., Severino, R.S., Drummond, S.S., Campos, D.B., Santana, M.I.S., De Moraes, D.D.A. (2008). Origin and distribution of the ischiatic nerves in goats of the Saanen breed. Ciencia Rural. 38: 372-377. DOI: 10.1590/S0103-84782008000200012.

Dursun, N. (2000). Veteriner Anatomi III. Medisan Yayın Serisi: 47, Ankara 2000. ISBN: 975-7774-44-8. p. 90-148.

Dyce, K.M., Sack, W.O., Wensing, C.J.G. (2017). (Çeviri Editörleri: Haziroglu, R.M., Cakir A.) Veteriner Anatomi Konu Anlatımı ve Atlas (Dördüncü Baskı). ISBN: 978-975-277686-9. Güneş Tıp Kitabevleri, Ankara.

Erden, H. (1992). Akkaraman koyunu ve Ankara keçisinin plexus lumbosacralis'i üzerinde karşılaştırmalı makroanatomik ve subgros çalışmalar. Eurasian Journal of Veterinary Sciences. 8: 45-50.

Ghoshal, N.G. (1966). A comparative morphological study of the somatic innervation of the antebrachium and manus. Crus and Pes of the Domestic Animals (Bovidae, Ovidae, Capridae, Suidae, Equidae). Unpublished Ph.D. thesis, Library, lowa State University, Ames, lowa.

Ghoshal, N.G., Getty, R. (1967). Innervation of leg and foot in the ox (Bos taurus), sheep (Ovis aries) and goat (Capra hircus). Indian Journal of Animal Health. 6: 59-73.

Ghoshal, N.G., Getty, R. (1968). A comparative morphological study of the somatic innervation of the crus and pes of the domestic animals (Bos taurus, Ovis aries, Capra hircus, Sus scrofa domesticus, Equus caballus). Iowa State Journal of Science, 42: 297-310. 
The Branching Pattern of the Nervus Ischiadicus after Passing through the Foramen Ischiadicum Majus in Hasak Sheep Breed

Ghoshal, N.G., Getty, R. (1971). The lumbosacral plexus (plexus lumbosacralis) of the sheep (Ovis aries). New Zealand Veterinary Journal. 19: 85-90.

Godinho, H.P., Cardoso, F.M., Nascimento, J.F. (1987). Anatomia dos ruminantes domésticos. Belo Horizonte: Universidade Federal de Minas Gerais, p. 438.

Karabacak, A., Aytekin, I., Boztepe, S. (2015). Fattening performance and carcass characteristics of Akkaraman lambs indifferent housing systems. Indian Journal Animal Research. 49: 515-522.

Kaymakci, M. (2008). Crossbreeding experiments with Turkish Native sheep breeds. Hayvansal Uretim. 49: 43-51.

Nirban, L.K., Joshi, R.K., Narula, H.K., Singh, H., Bhakar, H. (2015). Estimates of heritability for growth and wool traits in Marwari sheep at arid region of Rajasthan. Indian Journal Animal Research. 49: 872-874.

Nomina Anatomica Veterinaria. (2017). Nomina anatomica veterinária. $6^{\text {th }}$ ed. International Committee on Veterinary Gross Anatomical Nomenclature, World Association on Veterinary Anatomist. Published by the Editorial Committee Hanover (Germany), Ghent (Belgium), Columbia, MO (U.S.A.), Rio de Janeiro (Brazil).

Pasquini, C., Spurgeon T., Pasquini, S. (1995). Anatomy of Domestic Animals (Systemic and regional approach). $7^{\text {th }}$ Edition. Sudz Publishing, 1222S. HWY. 377 P.O. Box 1199 Pilot Point, TX 76258 USA ISBN: 0-9623114-2-1.

Resmi Gazete (2014). (12 Kasım 2014; Sayı: 29173). Yerli Hayvan Irk ve Hatlarının Tescili Hakkında 2004/39 No'lu Tebliğde Değişiklik Yapılmasına Dair Tebliğ (Tebliğ No: 2014/50).
Sonmez, R. (2009). Sheep Breeding Research in Turkey. Uludag Universitesi Ziraat Fakultesi Dergisi. 23: 43-65.

Tekin, M.E., Gurkan, M., Karabulut, O., Duzgun, H. (2000). Merinos, Akkaraman and İvesi Irklarının Bazı Etçi Irklar ile Melezlerinde Performans Test and Seleksiyon Çalışmaları, (Tip Sabitleştirmesi: Hasmer, Hasak, Hasiv, Linmer). Sonuç Raporu, Proje Kod No: TAGEM-IY97-10-03-009.

Tekin, M.E., Gurkan, M., Karabulut, O., Duzgun, H. (2005). Performance Testing Studies and the Selection of Hasmer, Hasak, Hasiv and Linmer Crossbreed Sheep Types: II. Pre-Weaning Growth. Turkish Journal of Veterinary and Animal Sciences. 29: 59-65.

Vasconcelos, B.G., Santos, M.C.D., Santos, A.C., Viana, D.C., Honorato, A.G.O., Pereira, C.C.H., Borelli, V., Silva, F.O.C. (2014). Origin and distribution of the ischiatic nerve in mixed-breed sheep. Brazilian Journal of Veterinary Research and Animal Science. 51: 102-110. DOI: 10.11 606/issn.1678-4456.v51i2p102-11.

Verma, R.K. and Sharma, N.K. (2009). Knowledge of sheep farmers about improved sheep production technologies. Indian Journal of Animal Research. 43: 275-278.

Yilmaz, O., Cengiz, F., Ertugrul, M, Wilson, R.T. (2013). The domestic livestock resources of Turkey: Sheep breeds and cross-breeds and their conservation status. Animal Genetic Resources. 52: 147-163.

Zeder, M.A. (2008). Domestication and Early Agriculture in the Mediterranean Basin: Origins, Diffusion and Impact. Proceedings of the National Academy of Sciences of the United States of America. 105: 11597-11604. doi:10.1073/ pnas. 0801317105 . 